\title{
Currency exchange: Implications for plastic surgical practice
}

\author{
Daniel A Peters MD MBA FRCSC ${ }^{1}$, Douglas R McKay MD MBA FRCSC ${ }^{2}$
}

$\mathrm{O}^{\mathrm{n}}$ January 7, 2016, Stephen Poloz, the Governor of the Bank of Canada, delivered a speech at Ottawa City Hall (Ottawa, Ontario). In this speech, he commented on the implications of a divergence in the Canadian and American macroeconomy. The Canadian economy is resource based and Canada is a net exporter of natural resources. In contrast, the United States (US) is a net importer of natural resources. The decline in consumption of such resources, particularly in emerging economies such as China, has resulted in decreased demand for Canadian dollars and a decline in the value of our currency. In contrast, as a net importer of natural resources and exporter of finished goods and services, the American currency has strengthened in this environment.

The divergence in these two economies is an unusual phenomenon and has important implications for currency exchange. The US Federal Reserve has begun to increase interest rates in an effort to manage inflation. This has resulted in a strengthening of the American dollar relative to other global currencies. Conversely, there is persistent weakness in demand for Canadian dollars. Mr Poloz asserted that the Bank of Canada has no intention of escalating the benchmark rate, which has the monetary effect of compounding Canadian currency weakness. This divergence in monetary policy between the two economies will further erode the value of Canadian dollars relative to their American counterparts.

Devaluation of Canadian currency will result in escalation of prices, particularly for imported goods and services. Such price increases will invariably result in elevated levels of inflation across the economy. Such inflation will likely be unevenly distributed. In the short term, the price level for imports will likely rise more quickly than demand for services that are locally produced and sold. Eventually, such inequities will adjust and inflation will increase throughout the economy.

Plastic surgery often requires purchasing a significant number of factors of production. Plastic surgeons purchase myriad goods and services. These include sutures, drapes, implants, injectables, cosmetics, custom implant design, anesthetic agents and medications. Many of these are imported through large multinational corporations. Johnson \& Johnson has its headquarters in Brunswick, New Jersey (USA). Allergan has been purchased by Pfizer and has its corporate headquarters in New York city (New York, USA). Medtronic is headquartered in Dublin (Ireland). None of the major suppliers to Canadian plastic surgeons has its primary operations cited in Canada. While, there are certainly Canadian divisions and Canadian sources of production, many of these companies will face pressures from currency exchange.

Some of these companies will adopt internal methods for managing global currency fluctuations. However, a significant and persistent decline in currency values in a specific market will invariably result in inflation within that market. Furthermore, from the perspective of the plastic surgeon (who is a consumer of these factors of production) there is an expectation that the overall prices will increase. This will mean that plastic surgeons will face an increase in the cost of direct factors of production.
As inflation rises, wages tend to rise to achieve parity in purchasing power. For example, as nurses, administrators and other staff recognize the decreased ability of their wages to cover their required expenditures, they often request and receive increased cost of living adjustments (COLAs). This will mean that the cost of the entire gamut of factors of production will increase encompassing both goods and labour.

The changes in currency and anticipated rise in inflation will have significant implications for the profitability of a plastic surgical practice. As costs escalate, plastic surgeons will be confronted with alternatives to preserve net income and free cash flow. They will either need to mitigate cost increases or devise strategies for increasing revenue.

The control of cost to mitigate the escalation in a price level is termed a 'hedge against inflation'. The concept is that strategies can be instituted that would enable the business person to mitigate losses from currency fluctuations. These hedges can be considered in three groups: currency trading; contractual arrangements for providing price stability; and, finally, a shift in services from areas that are vulnerable to areas of decreased exposure. We shall consider the implications of each in turn.

Some plastic surgeons may consider converting their working capital into another currency. Working capital is the amount of money required to keep the business running on a daily basis. It does not include the cash required for large capital acquisitions. It usually encompasses the amount of cash required to meet payroll and purchase supplies for 12 months. There may be some advantages to keeping working capital in American dollars. Most companies that supply plastic surgeons use American dollars as base currency and, thus, suppliers would emulate any fluctuations. This means that fluctuations in the Canadian dollar would not affect any purchases.

The difficulty with this strategy is that we may have already missed the opportunity to pursue this as an effective means. As we write these words, the Canadian dollar is trading at approximately USD $\$ 0.70$. It is unclear how much further devaluation will occur. However, at this point, purchasing power has already been substantially eroded. Each individual will need to posit a theory of the current currency trend. However, this hedge is clearly predicated on an understanding that devaluation has already occurred.

The second strategy is to consider contractual means of hedging. Canadian inflation is currently $1.4 \%$. The Bank of Canada has set the target rate of inflation between $0 \%$ and 3\%. Monetary policy is likely to maintain inflation within this range. Therefore, there has been no indication of rapidly expanding inflation at the present time. If one would expect a delay for the impact of currency devaluation to permeate the economy and result in escalation costs, then one could consider negotiating a longer-term contract for inputs. For example, many plastic surgeons agree to purchase implants from a supplier on a caseby-case basis, with additional volume-based discounts. One may consider whether contracts should be devised that would be longer term and incorporate price guarantees. If one expects the costs of implants to rise substantially, he or she could negotiate a price guarantee with

${ }^{1}$ Division of Plastic Surgery, Department of Surgery and Telfer School of Management, University of Ottawa, Ottawa; ${ }^{2}$ Division of Plastic Surgery, Department of Surgery; Queen's University, Kingston, Ontario

Correspondence: Dr Daniel A Peters, Division of Plastic Surgery, Department of Surgery and Telfer School of Management, University of Ottawa, PO Box 213, 1053 Carling Avenue K1Y 4E9. E-mail dannypeters1@gmail.com 
the supplier over a defined period of time, say two to three years. While this may decrease flexibility in purchasing, it may provide stability in pricing and mitigate inevitable increases that accompany an inflationary environment.

Similar strategies can also be incorporated with labour contracts. Many contracts incorporate COLAs based on real dollars or dollars above inflation. In such circumstances, employers are responsible for increasing wages based on inflation and another incremental increase. Contracts constructed in such a fashion in an inflationary environment can result in uncontrolled costs. However, contracts can be constructed that stipulate the extent of COLAs without incorporating inflation as a base rate. For example, many contracts stipulate a $3 \%$ COLA above the base rate of inflation. If inflation were taken at $5 \%$, this would imply an $8 \%$ annualized wage increase in nominal dollars. Some employees may prefer a 5\% COLA without any regard to inflation. The employer is then taking a risk of assuming that inflation will be $>2 \%$. In the event that inflation maintains its current position of $1.4 \%$, this would be disadvantageous to the employer. However, in a more inflationary environment of $5 \%$, this would result in significant savings.

The third hedge is to consider switching to goods and services that require fewer vulnerable inputs. For example, breast implants and injectibles may be more susceptible to price fluctuations. Procedures in which fewer inputs are required, such as facelifts, blepharoplasty and abdominoplasty, may be less vulnerable. Of course, there are multiple other factors that would influence this type of decision.

While hedges against increasing cost can be managed through the above strategies, the other alternative is to anticipate escalating inflation and to allow the prices of the goods and services offered by plastic surgeons to rise gradually in anticipation of this environment. This requires a thorough evaluation of the present market in which the surgeon operates, including demand elasticity. In some markets, even a small change in price may result in diminished quantity demanded, with resultant decreased profitability. In such an environment, this strategy may not be feasible. These market particulars notwithstanding, incremental anticipatory increases in price may be more readily tolerated than a sudden increase once an inflationary environment arrives.

There is a significant likelihood that Canada will face increased inflation and decreased foreign purchasing power. These macroeconomic trends will have important implications for plastic surgeons. It is important that all surgeons consider this environment and the strategies that can be used to mitigate erosion of profitability. Consideration at this early stage of these uncertain times could mitigate any harm. 